$$
\mathrm{DH} 337
$$


19 
AN IMPROVED AND PRACTICAL METHOD OF PACKING FISH FOR TRANSPORTATION

$\%$

By A. Sölling

Commissione' to the Danish Covenment Fisheries Defartment, London, Fngland

2

Paper presented before the Fourth International Fishery Congress held at Washington, U. S. A., September 22 to 26, 1908

BULLETIN OF THE BUREAU OF FISHERIES : : : : : : VOL. XXVII, P. 295-301

Document No. 659 : : : : : : : : : : : : : : : : : : lssued February, 1910 


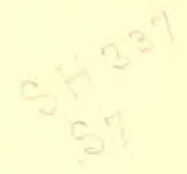

inf

$\vdots$ 


\title{
AN IMPROVED AND PRACTICAL METHOD OF PACKING FISH FOR TRANSPORTATION.
}

\author{
$\%$ \\ By A. SÖLLING, \\ Commissioner to the Danish Gonerment Fisheries Deparment, London, Enaland.
}

*

It was about forty years ago that ice was with good result first used on board English fishing ships for packing fish. Before that time fishing ships made only short voyages, to insure the fish reaching market in a good condition. But it was necessary to bring in the best and firmest fish only, those that could be kept fresh the longest time, such as soles, turbot, brill, and halibut, which fish retain the name of "prime fish." Other kinds of fish, such as plaice, cod, and haddock, could not be brought in, as they would not keep, and so had to be thrown overboard as useless.

In the eighties, when steam trawlers were introduced for fishing purposes, the fishermen went away for ten to fourteen days, sometimes three weeks, for their catch, and it was then necessary to make provision on board for a large quantity of ice, so that the catch might reach port in good condition. In spite of this precaution, however, a large quantity of fish caught at the commencement of the voyage was, and is still, landed in a very poor and stale condition, especially during the heat of the summer. People seem to enjoy iced fish, even though it has lost its flavor, believing that there is no possibility of procuring it otherwise. But when they have once tasted good fresh fish, cooked immediately after being caught and killed, they lose their taste for iced fish at once.

It was after seeing the poor treatment to which fish is exposed in England, from the moment it is caught-carried in ice in the trawler's hold, discharger and repacked, and finally laid out on the fishmonger's marble slab, occasionally being sprinkled with lukewarm water to make it shine-that I was led to experiment for a means of packing fish for transportation and keeping it in a better and sounder condition.

Many different experiments have been made in an effort to find the best and most practical means of keeping fish fresh and sound for a lengthened period, but all these methods, whether with or without the use of chemicals, have been found wanting in efficiency, the fish losing its fine appearance, and more especially its flavor. 
Freezing is a good and sound method of preserving, but it is difficult to keep the fish frozen in hot weather on long distances, as for instance on railway journevs. Moreover, on being thawed the fish lose their flavor, and they soon decompose on exposure to the deleterious influence of the air. Packing in ice is a method in very general use for transportation, but as the fish is constantly in close contact with the ice and ice water this method also has disadvantages. The idea in using ice is, of course, to keep the temperature low, thereby preventing decomposition as long as possible. But the exposure to ice and ice water destroys the flavor of the fish; they become stale, and when exposed to the air they quickly decompose, especially during mild weather.

The chief thing to be kept in view in preserving food is to keep it as free as possible from harmful bacteria and from the surrounding air charged therewith. It is, furthermore, necessary to prevent the ice water, which is also more or less full of bacteria, from coming into direct contact with the fish, but at the same time using the low temperature produced by the ice to prevent the further development of the bacteria invariably contained in the fish.

In using my method of wrapping fish in improved fish-wrapping paper and afterwards laying it in crushed ice, the latter in pieces about the size of a walnut, the air is excluded and the ice water prevented from coming in direct contact with the fish. The low temperature of the ice is acting directly on the fish through the paper, and by these means the fish is kept sweet and fresh for a longer period than is otherwise possible, the bacteria of decomposition being thus prevented from developing.

The chief point to be observed in this method of packing fish is that the fish be gutted and bled and the gills cut out as soon as possible after the fish are caught. The sound, found in some species, must be cut lengthwise to insure the removal of all blood particles underneath. Further, the fish should be cut open so far behind the vent that all accumulations of blood may be easily removed. They are then washed and scrubbed inside and out with a stiff brush in clean salt water, or in a solution of fresh water with 4 to 5 per cent of salt, until all blood specks have been removed, then they are laid aside for a short while to allow the blood and water to drain off, and very special care must here be taken that no water be left remaining on the inside. Each fish is then carefully wrapped in the wrapping paper, which is cut square, each dimension being at least one and a half times the length of the fish.

To wrap, place the fish across the nearest corner of the sheet, roll it over very firmly, turn in the two side corners, and roll the package over again until the fourth corner is reached, then tie with a piece of twine.

Objection might be raised that too much trouble is involved in treating fish in the above manner, and that it takes too much time. But the time, 
trouble, and small expense incurred are very soon repaid by the higher prices which are obtainable for the fish, owing to their far better appearance, and to the very important fact that they will keep fresh after fish that have been treated in the old way have spoiled. The fishmonger, too, will soon find his profit in having for sale fish which not being sold to-day will turn out just as fresh eight or fourteen days hence, even in the hottest weather. It may be remarked that all kinds of fish may not profitably be treated according to this method, but prime fish, such as soles, turbot, brill, halibut, and haddock, perhaps cod and plaice, will fetch a much higher market price if so treated.

The more expensive fresh-water fish, such as salmon, carp, and trout, are always shipped in ice without being gutted, but even they would have a far better appearance if wrapped in this paper instead of being exposed to the influence of air and ice water. I would here, however, draw attention to the fact that the fundamental feature of my method of wrapping fish is that the fish be gutted, that the entrails and the gills be removed, and the fish thoroughly washed.

The first important experiment with the method here presented was carried out in October, 1905. The necessary fish were caught by special permission of the Danish Government in the steamer Thor, which otherwise was engaged in international sea investigations. For the purpose of comparison the fish were packed in four different ways:

I. Gutted, wrapped in paper, and laid in ice.

2. Not gutted, wrapped in paper, and laid in ice.

3. Gutted and, without paper, laid in ice.

4. Not gutted and, without paper, laid in ice.

Altogether 147 fish were packed in these different ways. The flat fish included soles, turbot, brill, plaice, lemon soles, and whitches; the round fish were haddock, cod, whiting, hake, and gournard.

On October 6 and 7 the fish were packed, and on October 17 the method was explained and specimens of the different kinds of fish were shown to people interested, including press representatives, fishmongers, and others well acquainted with such matters. The following results were revealed:

I. The fish gutted and wrapped in paper and ice were perfectly white and firm, without any smell whatever, the skin was not discolored, and most of the fish had retained the stiffness of death.

2. The fish not gutted but wrapped in paper and ice were in most cases damaged in the inside.

3 and 4 . The fish gutted and not gutted (round) and not wrapped in paper but placed in direct contact with air and ice water were soft and stale and the shin discolored. 
On Octoher 2I, fifteen days after having been wrapped, some of the fish packed under method no. I were taken out and examined. Seven different kinds, after being boiled, were found perfectly fresh and to have retained their flavor in full.

Another test, the following spring, gave results as follows:

On March 26, I 906, 3 halibut weighing about 2 stone each were packed in Grimsby, according to my method, and the same day sent by steamer to Copenhagen in a box containing ice. To afford a comparison, a fourth halibut, treated exactly as the others except that it was not wrapped in paper, was inclosed in the same box.

On April 9, after having been wrapped up for fourteen days the first halibut was taken out, and I was informed (not being present myself) that it was found perfectly fresh and without any discoloring of the skin at all. The halibut which had not been wrapped in the paper and therefore had remained in direct contact with the ice was discolored on the skin and was quite stale.

On April 20, after being wrapped for twenty-five days, the second halibut was taken out in the presence of several well-known gentlemen, when I also was present. It was found fresh, firm, and white in the flesh, and, after being cooked, to have retained its full flavor.

On April 26, after being wrapped for thirty-one days, the third and last halibut was taken out, and found to be firm and white and also without any discoloring of the skin. It was tasted by several people, myself included, and found to have retained its full flavor.

A third practical experiment was carried out by order of the Royal Greenland Trading Company, of Copenhagen. Thirty-nine halibut caught in Davis Strait were treated according to my method on August i 2, I906, and forwarded in boxes filled with ice in the steamer Hans Egede, which landed them at Peterhead on September I. The fish, in the boxes, were sent by rail to Grimsby, where they arrived in splendid condition and were sold on September 3, fetching a comparatively high price.

Upon the basis of the different experiments, I can safely affirm that by wrapping fish in this manner and treating them as described they can be kept fresh for a much longer period than is possible by the old method. Further, in consequence, the fish will prove to be a far better and more healthy food when treated in this manner than when kept in direct contact with air and ice water.

I would mention in conclusion that my method of packing need not be limited to fish. Meat also will keep during the hottest weather when wrapped up perfectly fresh and laid in ice; and for experiment lobsters boiled in Canada have been sent to London. After being boiled and cooked, the lobsters were wrapped in the paper and sent in cases with ice, as a result retaining their full flavor for about fourteen days. 
The paper I use is called vegetable parchment, but I prefer to call it simply fish wrapping paper, for by employing this name I am able to retard the use of bad initations with the consequent poor result and possibly damage to the reputation of my improved method of packing. 'The paper is at present to be had only in London. It is of two weights, the heavier parchment a dark brownish gray, the lighter weight a yellowish brown. The dark heavy paper, for wrapping large fish such as halibut, will shortly be made in sheets 5 feet square. The yellow paper, for wrapping smaller fish, is to be had in sheets 28 inches square. 
LIBRARY OF CONGRESS

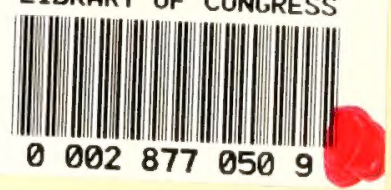


$S_{7}$ 
LIBRARY OF CONGRESS

|| || || ||| || || || || |||| || || || ||

Hollinger Corp. pH 8.5 